\title{
Student management systems in secondary schools
}

ROSEMARY HIPKINS and RACHEL DINGLE

\section{KEY POINTS}

- Principals were generally confident that their school used their student management system (SMS) effectively for a range of routine purposes.

- Principals were least likely to say the SMS could be linked to online areas where parents could access information about their child's progress.

- Compared to the principals, fewer teachers were confident that they could use the school SMS effectively for these same purposes. For example, 96 percent of principals said the school could effectively track literacy and numeracy credits for NCEA, while just 64 percent of teachers said they could effectively do this.

- A third of the teachers said they did not find the school SMS easy to use. A similar number said they had not had good training in using the SMS. 
How well is your school student management system (SMS) being used, by whom, and to do what? Principal and teacher responses to questions about this in the 2012 National Survey of Secondary Schools suggest this could be a fruitful area for schools to self-review.

\section{Introduction}

This article reports on one tiny "slice" of data from the $2012 \mathrm{New}$ Zealand Council for Educational Research (NZCER) National Survey of Secondary Schools. These national surveys take place every 3 years and are very wide ranging. Their overarching aim is to investigate the impact of policy initiatives such as changes to curriculum, assessment, school governance, or various forms of support for schools. Broadly, we could say that they look at whether policy initiatives "work" as intended. If so, what helps? If not, what contributing reasons can we see? For each survey round, a core set of questions are retained so that trends over time can be tracked. For example, the secondary survey always has questions about the National Certificate of Educational Achievement (NCEA), and recent primary surveys have included questions about National Standards.

In 2012 we added one small set of new questions about the use of student management systems (SMSs) in secondary schools. The next section explains why we saw this as a worthwhile addition to the mix. We then outline the teachers' and principals' responses to these questions and briefly discuss their implications for practice. The findings suggest that some judicious investment in professional learning that supports all teachers to be more effective users of the school's SMS would be timely, especially if the data stored there can then usefully inform teachers' classroom decision making and action.

\section{Why spend time pondering SMS use?}

Nearly every school now has a SMS and these could be evolving rapidly as technology improves and schools put in place more reliable information technology (IT) systems with broadband internet access. People from many different walks of life are now leveraging the processing "grunt" that potentially vast data networks provide to answer new and more complex questions about how the world works (Weinberger, 20II).

Are school professionals seeing the potential to use their SMS to think about their work in new ways-for example, by building more complex pictures of their students' actual and potential learning? What would it take to do this well? Obviously, one bottom line would be that all the school professionals who needed to be involved in data capture and use would be confident and competent to do so quickly and accurately. For most of the 2oth century this was never a part of teachers' work, or school leaders' work for that matter. So how are we going in 20I3? This article uses data from the 20I2 NZCER National Survey of Secondary Schools to paint a snapshot of current SMS use in secondary schools, and to point to some challenges that could be immediately addressed.

One of us (Rachel) often works to help schools set up reliable and accurate datacapturing systems and processes. She is well aware of the support that can be needed to do this well. Her experience has informed our reading of what the data are telling us. The other author (Rose) has wide experience of researching implementation of both The New Zealand Curriculum (Ministry of Education, 2007) and NCEA. Her experience brings a different perspective to the reading of the data, and their "so what?" implications for work in secondary schools.

\section{The research context}

NZCER's National Surveys are conducted 3-yearly, with the overall aim of documenting how new education policies and processes play 
out in practice. The 2012 secondary school survey took place during the third school term of that year. Four groups are surveyed in each round, but this article does not include any data from school trustees or parents. In 2012 all secondary principals of state and state-integrated schools were surveyed via a posted questionnaire, and all teachers on the New Zealand Post Primary Teachers' Association's (PPTA's) email database were surveyed via a web-based questionnaire.

The sample achieved was broadly representative of principals and teachers in New Zealand's secondary schools. More specific information about the sample can be found in the 2012 overview report which is posted on NZCER's website (Wylie, 20I3). This article reports on principal and teacher responses to questions about the use of SMSs in secondary schools.

Principals and teachers responded to a group of items that asked about how effectively the school made use of the SMSs for various specific purposes. Teachers were also asked about their personal use of the school's SMS. Principals were asked several yes/no questions to provide some context to their responses about usage. Fourteen percent said they had changed the SMS they used in the last I8 months. Almost half (49 percent) said the school employed someone to manage the student achievement data, while 64 percent said someone in their school held a specific role to analyse student achievement data and create reports for the principal and others to use.

\section{Principals' views about the school SMS}

Figure I shows that there was almost universal agreement that the SMS was used to track behaviours for which students are held accountablespecifically their attendance and general behaviour at school—as well as to generate individual student reports as needed. Similarly, almost all the principals agreed that the school SMS was used to check progress towards gaining the literacy and numeracy credits needed for NCEA. All of these activities could be seen as "bread and butter" aspects of the traditional work of secondary schools (albeit with a somewhat different focus in the case of tracking literacy and numeracy credits).

Notice that levels of uncertainty begin to appear below these items, with some principals giving neutral/ not sure responses. One reason for this might be that a specific function is delegated to someone else in the school and the principal is unsure how effectively it is carried out. We could, however, argue that keeping an overview of how effectively delegated roles are carried out is an important aspect of school leadership. Another reason could be that some schools have not yet tried to do some of these things, and so are uncertain if their current SMS could do them effectively. ${ }^{1}$ This seems a more likely explanation given that activities with higher uncertainty levels are relatively newer uses of the SMS, compared to those activities that principals thought were being carried out routinely and well.

The bottom-ranking item is the least traditional of all. A third of the principals ( 32 percent) were clear that the school did not use the SMS as a means of sharing information with parents about the progress of their own child. A further I4 percent were unclear if this was happening effectively. Just under half thought that the school SMS was used to do this effectively, and, as we will

\section{FIGURE 1. SECONDARY PRINCIPALS' REPORTS OF EFFECTIVE SCHOOL SMS USE $(N=177)$}

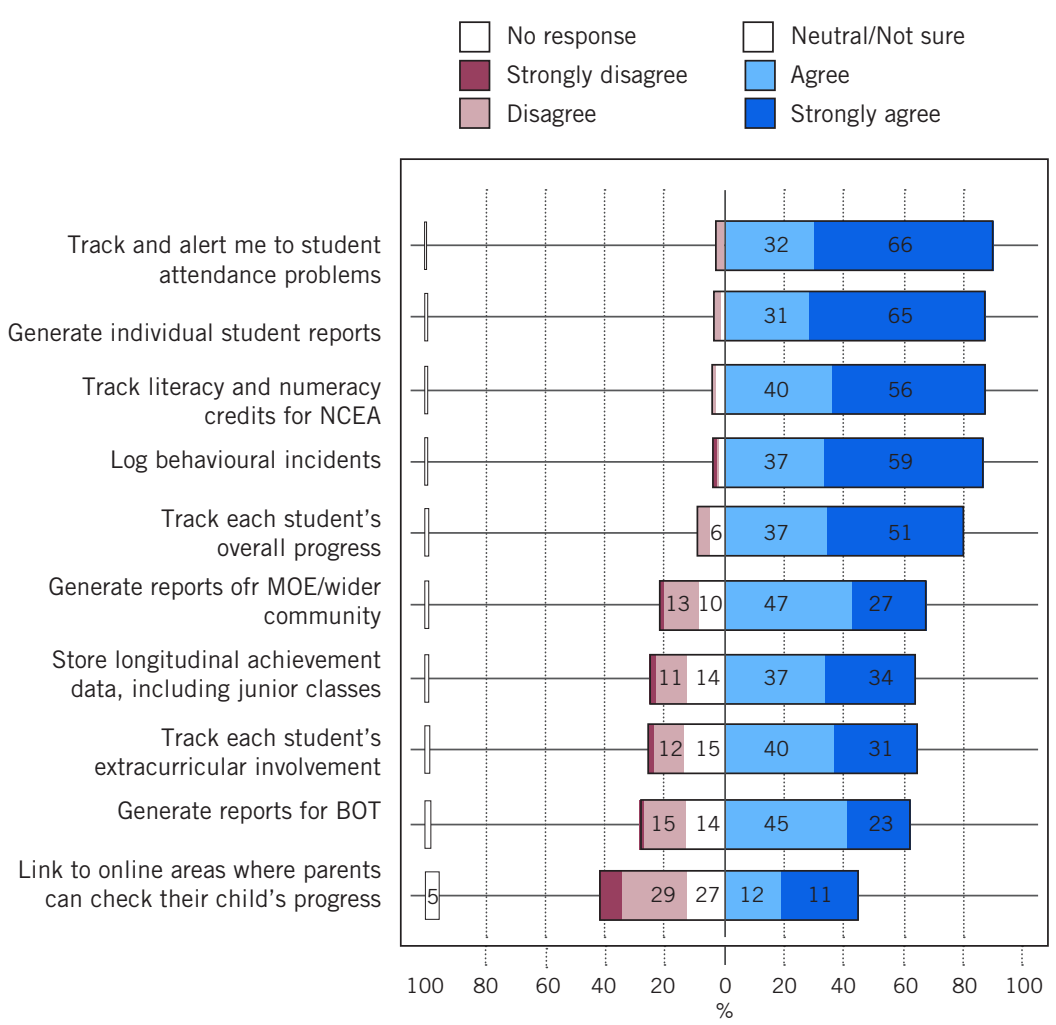


shortly see, confidence that this was happening was much lower still among teachers.

There were some patterns of differences related to school characteristics. Principals in decile I or 2 schools were somewhat more likely than other principals to disagree that they used the SMS effectively to store longitudinal achievement data, while those in decile 9 or Io schools were somewhat more likely to strongly agree that the school's SMS was used effectively to track students' overall progress. Decile I and 2 principals were less likely than other schools to assign analysis of the data as a specific role: just 40 percent of these principals said they did this, compared with two-thirds (67-68 percent) of other principals.

Principals of the very largest schools (I50o+ students) were overrepresented amongst those who strongly agreed that they used the SMS to track student attendance, and they were also the most likely to say that they employed someone to manage the data: 82 percent of principals in the biggest schools said this, compared to 23 percent of those in schools with 200 students or fewer. This makes sense, given that data entry requirements expand in direct proportion to the number of students, and it is easier for some students to get "lost" among the masses in a bigger school.

\section{Teachers' views about the school SMS}

Eight of the items from the principals' survey were also included in the teacher survey. Rather than being asked how effectively the school used the SMS, teachers were asked how easily they personally could do these things. Figure 2 shows teacher responses. When comparing the teachers' responses with those of the principals, it is important to note that these are not matched sets: we had teacher responses from schools where the principal did not respond, and vice versa. Even so, it is noticeable that nationally, compared to principals, lower proportions of the teachers said that they could effectively use their school's SMS for any of the purposes stated.

Comparing teachers' responses with those of the principals, several differences stand out. The biggest differences were in relation to tracking student achievement data longitudinally (a 34 percentage point difference for agree/strongly agree responses), tracking each student's extracurricular involvement and tracking literacy and numeracy credits for NCEA (both 32 percentage point differences). Notice that two of these are also activities about which at least a quarter of the responding teachers were unsure.

All three of the activities with higher unsure/neutral responses, by their nature, would span different classes and teachers. It seems that some teachers simply did not know if they were happening, and others did not do these things themselves. It is notable that senior leaders' perceptions seemed to be closer to those of principals: they were more likely than all other teachers to agree that they could effectively use the SMS to carry out almost all the described activities. (The exception was to link to an online area where parents could check their child's progress.)

Teachers in decile I or 2 schools were more likely than others to strongly agree that they could use their school's SMS to effectively: track and raise alerts about attendance problems; log behavioural incidents; track students' overall progress; generate individual student reports; and store longitudinal achievement data. Teachers in decile 9 or Io schools were more likely to be unsure or to disagree that they could use the SMS to track literacy and numeracy credits. These responses paint a rather different picture than those made by the principals. What are we to make of the seeming contradictions? One explanation could be that some teachers in low-decile schools can do more than their principals know.

\section{FIGURE 2. SECONDARY TEACHERS' REPORTS OF HOW EFFECTIVELY THEY} COULD USE THEIR SCHOOL'S SMS $(N=1266)$

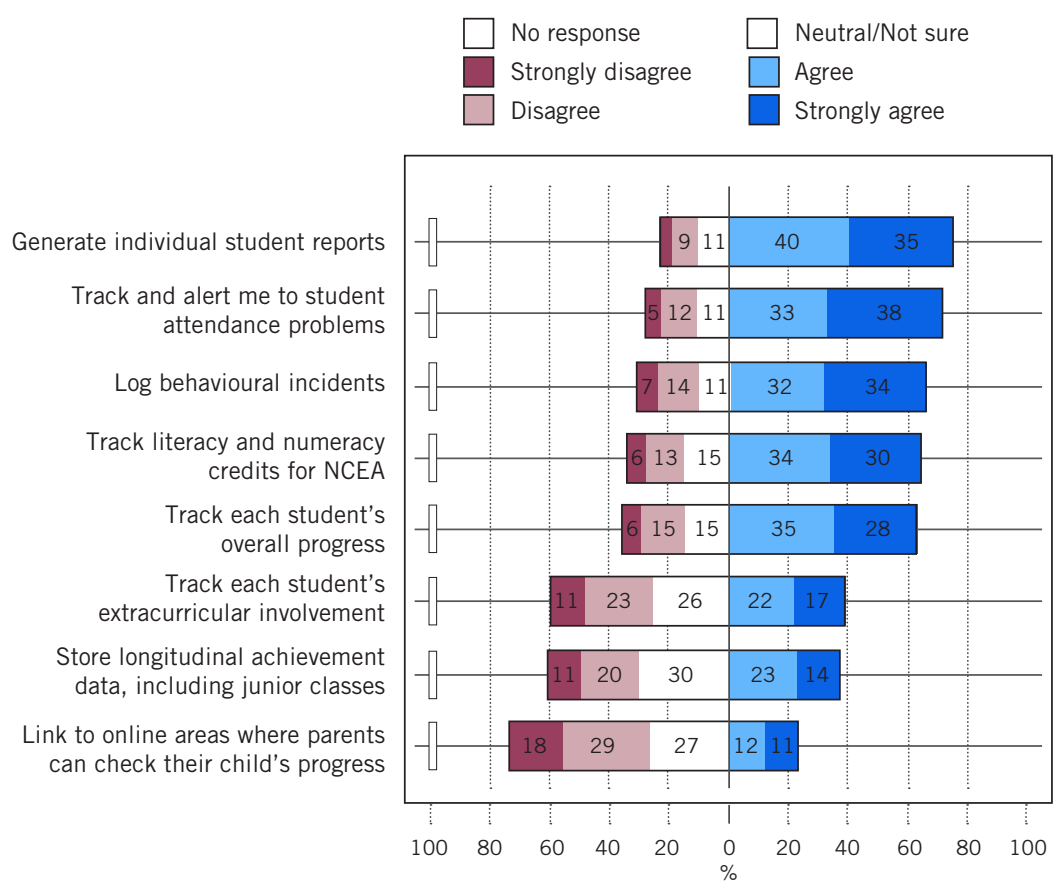


TEACHING AND LEARNING

Several large teacher professional learning initiatives, targeted to lowdecile schools, have included a strong focus on collecting and using data to inform teaching and learning decisions, thereby keeping students on productive learning pathways and trajectories. Examples include the Starpath initiative in Auckland schools (see, for example, McKinley et al., 2009) and the school-wide initiative which is part of $\mathrm{PB}_{4} \mathrm{~L}$ (Positive Behaviour for Learning). The focus of such initiatives is on proactive use of the data rather than retrospective reporting, but this is only possible with the active involvement of all the teachers. For that to happen teachers need to be able to use their school's SMS efficiently and with comparative ease. So how confident do they feel about their personal SMS use?

\section{Teachers' views about their personal SMS use}

As well as responding to items about what the school did, teachers were also asked several yes/no questions about their personal SMS practice. Table I shows the results.

Notice that between a third and half of the teachers said they did not find their school's SMS easy to use in general, nor could they easily retrieve data for all the students in their classes or generate a nonstandard list of names. It doesn't seem to be a coincidence that similar numbers felt they had not received good training in the use of the school SMS. Nevertheless most of them did not avoid using the SMS, and indeed had to enter student data themselves.

There are obvious implications here for teachers' workloads. But the question of whether they should be relieved of some of the grunt of using a SMS is not a straightforward one. In Rachel's experience, data are likely to be much "cleaner" when teachers

TABLE 1. SECONDARY TEACHERS' PERSONAL SMS USE $(N=1266)$

\begin{tabular}{|l|c|c|c|}
\hline Statement & $\begin{array}{c}\text { Yes } \\
\%\end{array}$ & $\begin{array}{c}\text { No } \\
\%\end{array}$ & $\begin{array}{c}\text { Don't } \\
\text { know \% }\end{array}$ \\
\hline I have to enter student achievement data myself & 88 & 7 & 2 \\
\hline I find the SMS easy to use & 65 & 30 & 4 \\
\hline $\begin{array}{l}\text { I can easily retrieve achievement data in all subjects for the } \\
\text { students in my class }\end{array}$ & 63 & 29 & 6 \\
\hline I have had good training in how to use the school's SMS & 57 & 37 & 4 \\
\hline $\begin{array}{l}\text { I can easily generate a list of names for a nonstandard student } \\
\text { group (e.g., a specialist class drawn from several different } \\
\text { form groups) }\end{array}$ & 48 & 41 & 9 \\
\hline $\begin{array}{l}\text { The school has someone whose role it is to analyse student } \\
\text { achievement data and provide teachers and management with } \\
\text { reports }\end{array}$ & 35 & 52 & 11 \\
\hline In the last 18 months my school has changed its SMS system & 19 & 71 & 8 \\
\hline I avoid using the SMS & 14 & 80 & 3 \\
\hline I only use the SMS to enter lesson-by-lesson attendance & 13 & 81 & 3 \\
\hline
\end{tabular}

Note: Numbers may not add to Ioo because of rounding and a small number of non-responses

enter the details themselves. A dataentry person who does not know the students might not spot errors that their own teacher would immediately see. Similarly, in Rachel's experience, teachers who learn to use the SMS effectively have a better chance of developing a rich and complex "feel" for students' learning trajectories and progress. Accurate data are obviously more reliably useful, so other ways might need to be found to solve the workload problems, if higher value is going to be placed on more comprehensive and complex use of SMS to help raise student achievement.

Congruent with their response concerning the effective use of the school's SMS, teachers in decile I and 2 schools were somewhat more likely than their peers to say that the school's SMS system was easy to use and that the school employed a person to do the data analysis. They were also more likely to say that they did not have to enter achievement data themselves, which, as outlined above, is not necessarily a straightforwardly "good thing". Teachers in decile 9 and ro schools were more likely to say it was not easy for them to access achievement data for all the subjects taken by students in their class.
Compared with other aspects of the 2012 NZCER National Survey of Secondary Schools, there were markedly fewer differences related to the teacher's subject expertise. Teachers of English/languages, and mathematics/science or computing, were somewhat more likely to say the SMS was easy to use. This was the only substantive difference in relation to main subject taught.

Senior leaders were more likely than all other teachers to agree that they had received effective training in the use of the school's SMS and that it was easy to use. They were also more likely to agree that they could effectively use it to carry out most of the described activities, and to say that the school employed a person to carry out data entry.

Early career teachers (year I and 2) were less likely than all other teachers to say they had received good training in the use of the SMS, or that they could easily generate a list of names for a group. On the other hand, they were also somewhat less likely to say they had to enter achievement data themselves. Taking this task off them could constitute one way in which schools endeavour to keep early career teachers' workloads from seeming 
overwhelming. However, given the observations above about the value in developing a rich feel for one's own students' data, it could be useful to consider whether this is the most productive way to help early career teachers to manage their workloads.

\section{Looking ahead}

In his book Too Big to Know, David Weinberger talks about the "intertwingly" nature of the world that has been revealed by the more complex analyses that large databases and computer processing power have enabled (Weinberger, 20II). Wherever scientists look, they find more complex interconnections than they ever could have imagined or demonstrated with traditional evidence-gathering and analysis methods and tools. Teachers and school leaders have always known that students' learning is an intertwingly phenomenon, impacted on by so many aspects of life beyond school, as well as within it. In the past, this complexity could be leveraged to support learning where teachers knew their students really well, and were deeply linked in their local communities. There are many reasons why such conditions are less likely to pertain today, not least of them the size of schools (and classes within them) and the higher mobility of people all over the globe. The challenge implied here is whether SMSs can and should be used as an effective tool to keep track of the intertwingly nature of students' learning, so that teachers are better informed and enabled to support students' continuing achievement and progress. Whether we have the right tools for the job is one question. How well current SMSs are keeping up with the potential is another. Whether school professionals have the right skill mix and awareness of possibilities is a different question again. This article has addressed the latter, and what we have reported suggests that some investment in more effective SMS use would be timely, especially for teachers who are the pointy end of classroom decision-making and action.

\section{Note}

1 Rachel noted that it is not obvious how some SMS could be used to store longitudinal data, and it is not yet possible to do so with some of the systems still in use in schools.

\section{References}

McKinley, E., Madjar, I., van der Merwe, A., Smith, S., Sutherland, S., \& Yuan, J. (2009). Targets and Talk: Evaluation of an evidence-based academic counselling programme. Auckland: Starpath Project, The University of Auckland.

Ministry of Education. (2007). The New Zealand curriculum. Wellington: Learning Media.

Weinberger, D. (20II). Too big to know: Rethinking knowledge now that the facts aren't the facts, experts are everywhere, and the smartest person in the room is the room. New York: Basic Books.

Wylie, C. (2013). Secondary schools in 20I2: Main findings from the NZCER National Survey. Retrieved from: http://www.nzcer.org.nz/research/ publications/secondary-schools-20I2

ROSEMARY HIPKINS is a chief researcher at the New Zealand Council for Educational Research. Email: rose.hipkins@nzcer.org.nz

RACHEL DINGLE is a senior statistician at the New Zealand Council for Educational Research. 